\title{
Unique Recrystallization Resistance of Titanium Metastable $\beta$-Alloys Under Severe Hot Deformation
}

\author{
O.M. Ivasishin ${ }^{1}$, P.E. Markovsky ${ }^{1}$, M.Pozuelo ${ }^{2}$, S.V. Prikhodko ${ }^{2}$ \\ ${ }^{1}$ G.V. Kurdyumov Institute for Metal Physics, National Academy of Science of Ukraine, 36, \\ Vernadsky Blvd., 03142, Kiev, Ukraine \\ 2 Department of Materials Science and Engineering, University of California Los Angeles, Los \\ Angeles, CA 90095, USA
}

Titanium alloys of metastable $\beta$-class are superior over other titanium alloys due to the best combination of the highest strength level with other important properties: high strength-to-density ratio, good hardenability, excellent fatigue/crack-propagation behavior, and corrosion resistance [1, 2]. This combination is achieved at highest level in the solution-treated and aged alloys with fully $\beta$ transformed, fine-grained precipitation-hardened microstructure [3]. Different deformation techniques were applied to $\beta$-class titanium alloys to create the finest grain microstructure possible. However, such methods cannot be employed to produce commercially valuable amount of material. Some new intensive deformation techniques achieving true deformation $|\varepsilon|>1.3-1.5$ in one deformation pass can be applied for titanium alloys processing [4].

In this paper the influence of severe hot plastic deformation which combines forging + rolling was studied on two metastable $\beta$-class titanium alloys: VT22 (Ti-5.0Al-4.79Mo-4.70V-0.97Fe-0.71Cr (wt.\%)) and TIMETAL-LCB (Ti-1.50Al-6.82Mo-4.47Fe). Reduction of the cross section area for all tested samples during deformation (in single pass) was 75\%. Rolled samples were additionally annealed for checking their recrystallization ability. Structure of the samples after forging + rolling and after annealing was studied in longitudinal and transverse directions by light optical microscopy. Phase composition of the alloys was measured by x-ray diffraction (XRD). Crystallographic texture was evaluated using $\mathrm{x}$-ray diffraction texture unit. Internal grains structure and orientation were examined using electron backscattered diffraction (EBSD) and transmission electron microscopy (TEM). EBSD measurements were performed on Nova 450 (FEI). TEM results were obtained using JEM 2010 (JEOL). It was found that this type of severe deformation forms elongated notrecrystallized $\beta$-grains with sharp axial (110) $\beta$ texture, and fine $\alpha$-precipitates inside the $\beta$-grains. In as-deformed condition both alloys are characterized with high tensile strength (above $1500 \mathrm{MPa}$ ) and low ductility. Additional annealing at $\alpha+\beta$ temperatures does not change $\beta$-grain microstructure and texture, but gives essentially improved balance of strength and ductility. Obtained results are discussed in terms of possible mechanism of deformation accommodation.

[1] U.Zwikker, “Titan und Titanlegierungen” Springer-Verlag, Berlin, 1974, 687 p.

[2] G.Lutjering and J.C.Williams, "Titanium" Springer. 2003, 289 p.

[3] O.M.Ivasishin and R.V. Teliovich, Material Science and Engineering. A263 (1999) 142- 154.

[4] V.N.Vydrin, et al. "Theory and Technology of Rolling" Chelyabinsk, V.230 (1979) 77-82.

[5] The authors acknowledge Dr. V.O.Mushegyan (Paton-Armenia Company, Kiev, Ukraine) for performed forging + rolling of the alloys and Dr Krassimir Bozhilov (Central Facility for Advanced Microscopy and Microanalysis, University of California, Riverside, USA) for using facility for EBSD measurements. 

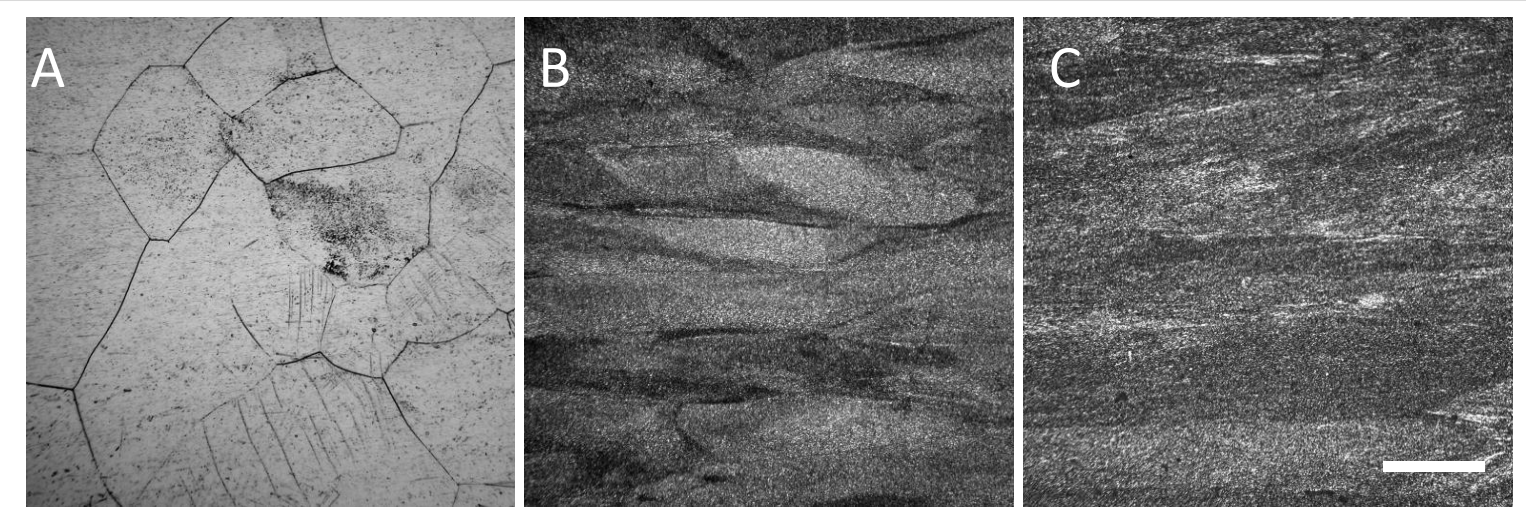

Figure 1. Microstructure of the alloy VT22. A. Structure before the hot plastic deformation. B. After forging + rolling. C. After annealing followed the rolling. All images are shown in longitudinal direction and at the same magnification. The scale bar is $200 \mu \mathrm{m}$.

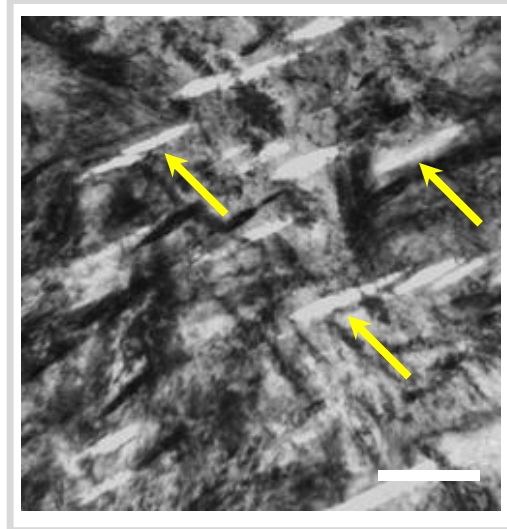

Figure 2. TEM image of alloy VT22 after forging + rolling. The structure shows high dislocations density within $\beta$-grains and fine $\alpha$-phase particles (arrowed) which precipitates during deformation. The scale bar is $200 \mathrm{~nm}$.
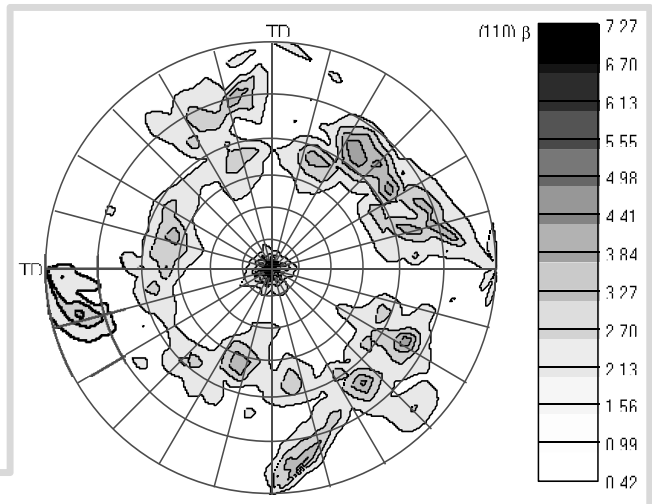

Figure. 3. Normalized (110) $\beta$ pole figure of VT22 alloy after deformation. TD are transverse to the rolling directions. The scale bar to the right shows normalized level of intensity of $\mathrm{x}$-ray beam.
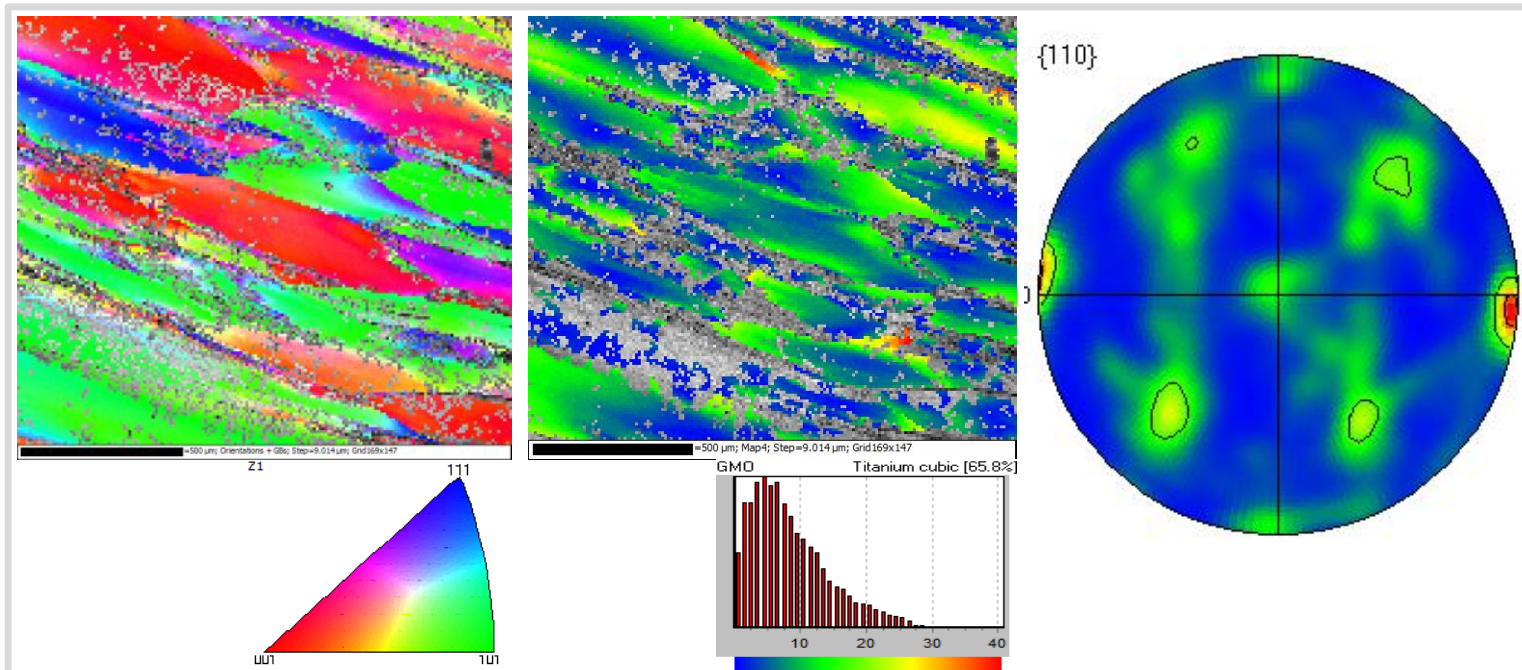

Figure. 4. EBSD results on the alloy VT22 sample atter torging + rolling and additional annealing. Left panel image (top) shows scanned area of the sample with the grains color-coded based on their crystallographic orientation in accordance stereographic triangle shown at the bottom. Image in the center panel shows the same area of the sample but the grains colored by misorientation relative to internal reference orientation of each grain. Right image shows the normalized (110) pole figure of the scanned area. Scale bar on the images is $500 \mu \mathrm{m}$ 